\title{
An eco-friendly and effective method to fabricate flame retardant cotton fabrics
}

\author{
Xiaotao Zhang ${ }^{1 *}$, Chunrong Zhou ${ }^{2}$, Haifeng Pan ${ }^{3}$ \\ ${ }^{1}$ School of Architectural Economics and Engineering Management, Hubei Business College, Wuhan, 430079, China; \\ ${ }^{2}$ School of intelligent manufacturing and automobile, Chongqing Vocational College of Transportation, Chongqing 402247, China \\ ${ }^{3}$ Faculty of Engineering, China University of Geosciences, Wuhan 430074, People's Republic of China
}

\begin{abstract}
To reduce the flammability of cotton fabrics, an environmentally benign, simple and effective method was proposed. Coatings composed of phosphoguanidine /ATMP /alginate were deposited on the surface of the cotton fabrics through layer-by-layer (LbL) assembly. FTIR spectra indicate that the layer-bylayer deposition process is successfully carried out on the surface of cotton fabrics. TGA suggested that LbL coating can significantly increase the char residue. The results of MCC and vertical flame tests showed that the LbL coatings can remarkably enhance the fire safety properties of the cotton fabrics and a higher concentration of ATMP $(2 \mathrm{wt} \%)$ can bring better effect of flame retardancy.
\end{abstract}

\section{Introduction}

Cotton fabrics is one of the most important natural textile fibers used to produce apparel, home furnishings, and industrial products, however, the low limiting oxygen index and combustion temperature $\left(360-425^{\circ} \mathrm{C}\right)$ makes the material highly flammable. Once ignited, cotton fabrics will burn rapidly, and the flame spreads quickly, potentially causing fatal burns within $15 \mathrm{~s}$ of ignition ${ }^{[1]}$. According to National Fire Protection Association statistics, there are approximately 17,300 mattress and upholstered furniture fires per year ${ }^{2]}$, which result annually in approximately 871 civilian deaths, 2230 civilian injuries, and $\$ 824$ million in property losses.

Therefore, various flame retardant additives have been used to modify combustion characteristics of textiles, including cotton fabrics. Halogenated and boroncontaining additives are widely used to improve the fire resistance of cotton fabrics, such as tris (2-chloroethyl) phosphate (TCEP), tris (1,3-dichloroisopropyl) phosphate (TDCPP) and tris (1-chloro-2-propyl) phosphate $(\mathrm{TCPP})^{[3]}$. Despite their effectiveness, the potential toxicity and environmental problems emerge from cotton fabrics storage, transportation and combustion. Recently, organophosphorus compounds are considered as suitable alternatives to halogenated flame retardants because of the advantages of environmentally friendly and high efficiency. Many studies have been conducted to investigate flame retardant mechanism of phosphorus nitrogen synergistic ${ }^{[4-7]}$. However, the preparation process reported is relatively complex, which could not meet the large-scale industrial production. Therefore, developing environmentally friendly, high efficiency and convenient operation techniques will be the best solution to flame retardant cotton fabrics for soft furnishings.

Layer-by-layer (LbL) assembly is a method to fabricate multifunctional, multilayer thin films on the surface of a substrate ${ }^{[8]}$. By submersing a substrate into positively and negatively charged polyelectrolyte and/or nanoparticle solutions, a positive-negative pairing layer is developed and comprised electrostatic, van der Waals, Hbonding, and covalent bonds ${ }^{[9]}$. Recently, the $\mathrm{LbL}$ assembly method was used to fabricate flame retardant coatings on various polymer matrices, including textiles, plastic plaques, and flexible polyurethane foams ${ }^{[10-12]}$.

In this study, three environmentally benign polyelectrolytes, phosphoguanidine, amino trimethylene phosphonic acid (ATMP) and alginate were deposited on cotton fabrics through layer-by-layer (LbL) assembly. The thermal stability and fire suppression of the coated and uncoated cotton fabrics were investigated. The mechanism of the enhanced fire safety of the coated cotton fabrics was proposed. It is anticipated that this multilayered coatings will provide a simple and green solution to reduce the fire hazards of cotton fabrics.

\section{Experimental}

\subsection{Materials}

Standard (untreated) cotton fabrics used in this study was received from Hengtai Cotton Fabric Factory of Jinzhou City. ATMP (50 wt \%) were supplied by Shanghai Dibai Chemical Technology Co., Ltd. Phosphoguanidine and alginate were supplied by Sinopharm Chemical Reagent Co., Ltd.

\footnotetext{
* Corresponding author: smiletao@163.com
} 


\subsection{Preparation of Solution}

Firstly, Phosphoguanidine solutions were prepared by adding $1.0 \mathrm{wt} \%$ Phosphoguanidine to deionized water. Then ATMP solutions were prepared by adding $1.5 \mathrm{wt} \%$ and $2.0 \mathrm{wt} \%$ ATMP. Finally, the alginate solutions were prepared by adding $0.4 \mathrm{wt} \%$ alginate to deionized water. All the solutions were vigorously stirred for $1 \mathrm{~h}$ until the polyelectrolyte was completely dissolved.

\subsection{Preparation of LbL assembly coating}

The standard size cotton fabrics were alternately sprayed by the phosphoguanidine solutions, ATMP solutions and alginate solutions. Every spray should ensure that the solution is evenly distributed on the cotton fabrics surface. Before spraying the next solution, the treated cotton fabrics should be placed in the vacuum blast drying oven 20 min to ensure it is completely dry. The preparation process is shown in Fig. 1 and the treated samples were marked as shown in Table 1.

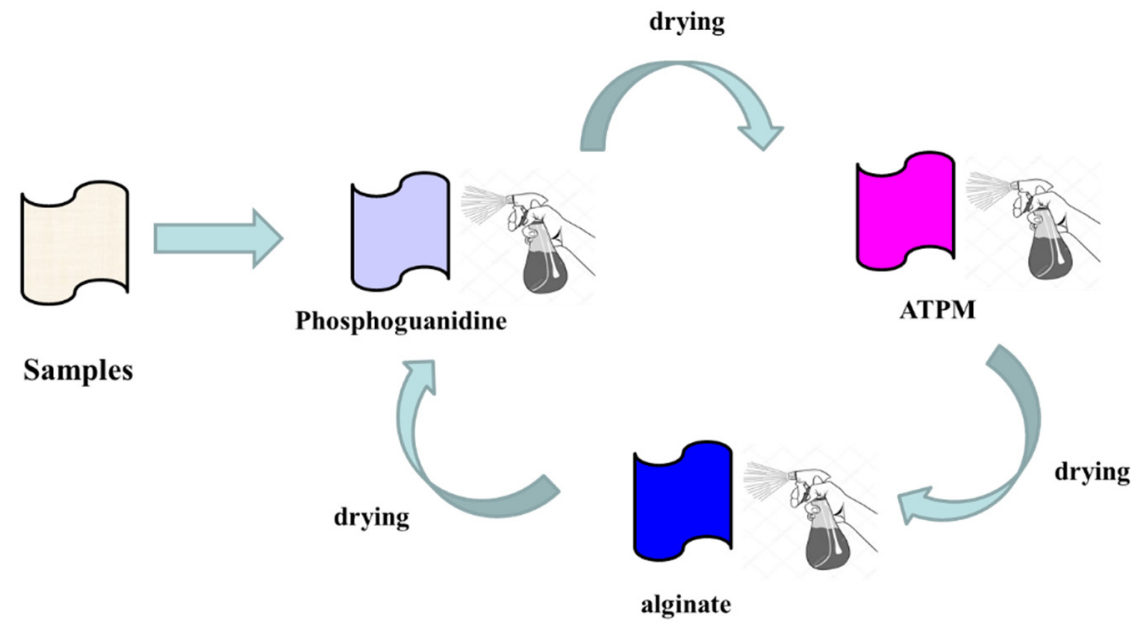

Figure 1. Scheme of layer-by-layer assembled deposition on the cotton fabrics.

Table1. Content of Phosphoguanidine /ATMP/ Alginate on the Surface of cotton fabrics

\begin{tabular}{ccccc}
\hline sample & Phosphoguanidine $(w t \%)$ & ATMP $(w t \%)$ & Alginate $(w t \%)$ & number of layers \\
\hline F1 & 1.0 & 1.5 & 0.4 & 1 \\
F2 & 1.0 & 1.5 & 0.4 & 2 \\
F3 & 1.0 & 2.0 & 0.4 & 3 \\
F4 (untreated) & 0 & 0 & 0 & 0 \\
\hline
\end{tabular}

\section{Characterization}

Fourier-transform infrared (FTIR) spectra of cotton fabrics were obtained on a Nicolet 6700 FTIR instrument. Samples were mixed with $\mathrm{KBr}$ powder and pressed into tablets, which was then placed in a ventilated oven. The transition mode was used and the wavelength range was set from 4000 to $500 \mathrm{~cm}^{-1}$.

The thermogravimetric analyzer (TGA) of samples under nitrogen atmosphere was examined on a TGAQ5000 apparatus (TA Company, USA) from 50 to $700{ }^{\circ} \mathrm{C}$ at a heating rate of $20^{\circ} \mathrm{C} / \mathrm{min}$.

Heat release rate (HRR) were measured in a microscale combustion calorimeter (GOVMARK MCC2). Samples of approximately $5 \mathrm{mg}$ were heated at a rate of $1 \mathrm{~K} / \mathrm{s}$ in a nitrogen stream flowing at $80 \mathrm{~cm} 3 / \mathrm{min}$. The degradation products of the sample in nitrogen atmosphere were mixed with a $20 \mathrm{~cm}^{3} /$ min stream of pure oxygen prior to entering a $900{ }^{\circ} \mathrm{C}$ combustion furnace.

Vertical flame tests were performed according to ASTMD 6413-08 using a vertical burning tester (CZF-3, Nanjing Jiangning Analytical Instrument Factory, China).
The samples (300 mm $976 \mathrm{~mm}$ ), held $19 \mathrm{~mm}$ over the Bunsen burner, were first exposed to the flame for a period of $12 \mathrm{~s}$ and then rapidly removed.

\section{Results and discussion}

\subsection{Characterization of cotton fabrics}

In order to provide a clear comparison, FTIR spectra of F3 and F4 cotton fabrics are depicted in Fig. 2. As shown in the Fig.2, compared to the F4 cotton fabrics, the bands at $1320 \mathrm{~cm}^{-1} \sim 1070 \mathrm{~cm}^{-1}$ of the $\mathrm{F} 3$ sample become smoother, which is probably attributed to the superposition of stretching vibration of $\mathrm{P}=\mathrm{O}$ and the $\mathrm{C}-\mathrm{N}$. The peak located at $870 \mathrm{~cm}^{-1}$ is assigned to stretching vibration of N-H. Moreover, the new characteristic peak at $1628 \mathrm{~cm}^{-1}$ and $1398 \mathrm{~cm}^{-1}$ appears that is corresponding to the antisymmetric and symmetric stretching vibration peaks of COO-. It is indicated that the layer-by-layer deposition process is carried out on the surface of F3 cotton fabrics. 


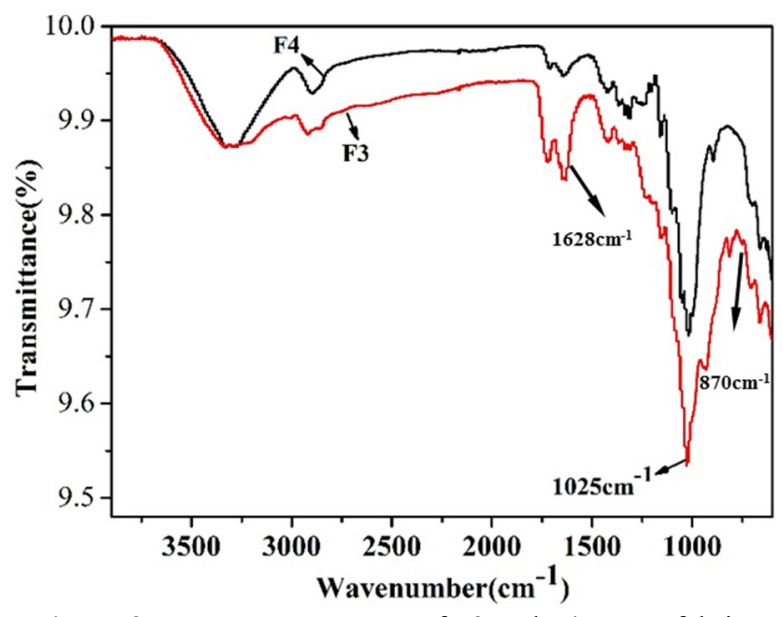

Figure 2. ATR-FTIR spectra of F3 and F4 cotton fabrics

\subsection{Thermal properties}

TGA provides direct information about the thermal stability and degradation mechanism by measuring the weight loss of the sample as a function of temperature. Fig. 3 present the TGA curves of the uncoated and coated cotton fabrics. It is can be seen from Fig.3, the pure cotton fabrics decomposition occurred in two main steps.

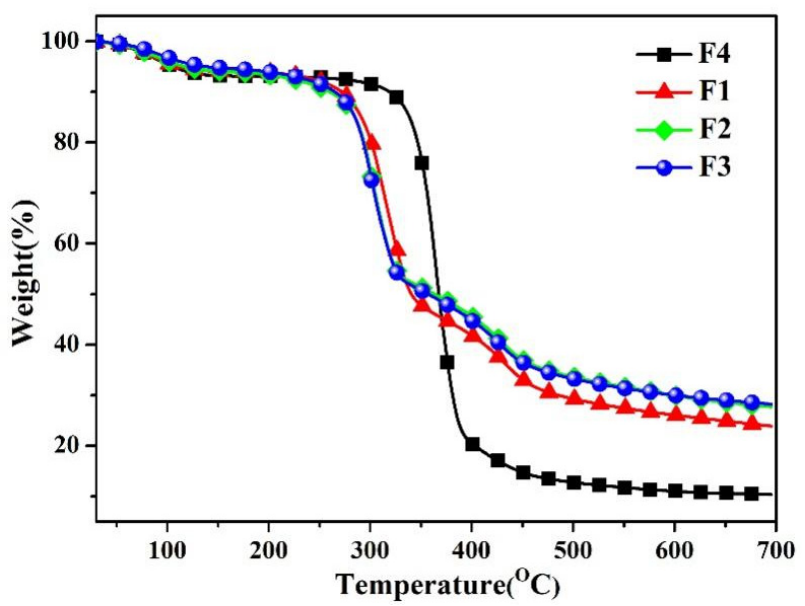

Figure 3. TGA curves of untreated and treated cotton fabrics

The first region around $360{ }^{\circ} \mathrm{C}$ is the main pyrolysis region, which shows significant degradation weight loss. And it is attributed to the dehydration and decarboxylation reactions . The second region around $400{ }^{\circ} \mathrm{C}$ is attributed to the further decomposition of residual char formed in the first region ${ }^{[13]}$. Meanwhile, for the treated cotton fabrics, the initial decomposition temperatures obviously decrease, which due to that the facile catalytic dehydration and cross-linking of cotton fabrics by phosphoric acid generated during pyrolysis of phosphorus-containing compounds. Another obvious phenomenon is that The coated cotton fabrics show higher solid char in the high temperature range $400{ }^{\circ} \mathrm{C}-650^{\circ} \mathrm{C}$. It is indicated that the formation of stable intumescent chars in the first stage, which can efficiently retard the diffusion of the oxygen and heat into underlying matrix.

\subsection{Flammability properties}

Microscale combustion calorimetry is an effective approach to obtain the information regarding combustibility and fire hazard of materials. Fig. 4 shows heat release rate (HRR) and curves of all samples that measured by MCC. It is can be seen from Fig.4, all coated cotton fabrics (F1-F3) have lower peak HRR and compared with untreated one (F4), indicating the improvement of flame retardancy for coated cotton fabrics. Another obvious result is that two distinct peaks can be found in the treated cotton fabrics HRR curve. The first HRR peak $\left(285-293^{\circ} \mathrm{C}\right)$ was associated with thermal decomposition of guanidine phosphate and sodium alginate in flame retardant components. The second HRR peak $\left(433-440{ }^{\circ} \mathrm{C}\right)$ was probably attributed to that the intumescent flame retardant system composed of sodium alginate and phosphate promotes charring and retards combustion reaction.

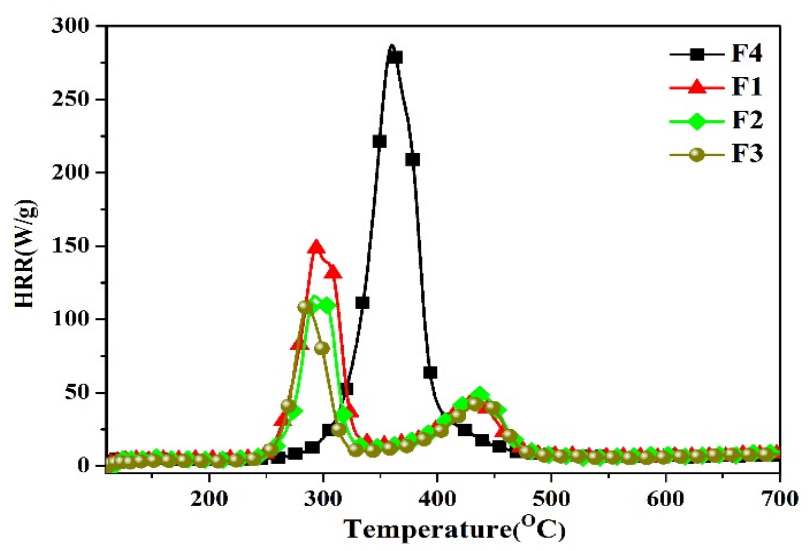

Figure 4. HRR curves of all cotton fabrics sample

The vertical flame test can be employed to evaluate the flammability of samples in the presence of flame spread. Fig 5 shows images of untreated and treated coated cotton fabrics after vertical flame test. As shown in Fig. 5, for untreated cotton fabrics (F4), there is no char left after the vertical flame test, indicating that the untreated cotton sample was completely consumed. For the F2 cottons, it was found that the char residues of these samples maintained their original shape. As for the F3 sample, the collected char residue is integral nearly with little slits on the bottom side and the char length is only $14.0 \mathrm{~cm}$, which is less than the $\mathrm{F} 3$ sample. It indicated that a higher concentration of ATMP (2 $\mathrm{wt} \%)$ can result in more content of ATMP on cotton fabrics and have highly effective flame retardancy. 
F2

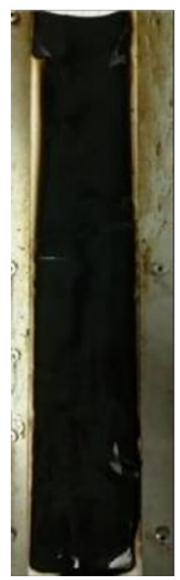

F3

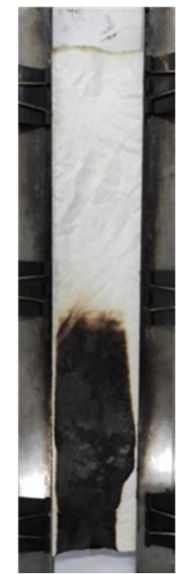

F4

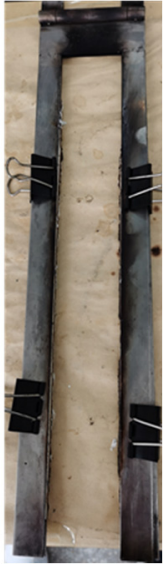

Figure 5. Vertical flame tests for untreated and treated cotton fabrics

\section{Conclusion}

Coatings composed of phosphoguanidine /ATMP /alginate were successfully deposited on the surface of cotton fabrics using a simple way that is layer by layer approach to improve the fire safety of the cotton fabrics. Coating analysis by TGA suggested that phosphoguanidine/ATMP/alginate LbL coating can significantly increase the char residue. Microscale combustion calorimeter results showed that the LbL coatings can remarkably enhance the fire safety properties of the cotton fabrics. Vertical flame test result show that a higher concentration of ATMP ( $2 \mathrm{wt} \%)$ can result in more content of ATMP on cotton fabrics and it will obtain highly effective flame retardancy.

\section{Acknowledgements}

This research was supported by Nature Science Foundation of Hubei Province under Grant No.2019CFB366.

\section{References}

1. Oulton, D. P. Fire-Retardant Textiles. In Chemistry of the Textiles Industry; Carr, C. M., Ed.; SpringerVerlag: Berlin, 1995; Chapter 3.

2. Ahrens M. Home fires that began with upholstered furniture. National Fire Protection Association, Quincy. 2020

3. H. M. Stapleton, S. Klosterhaus, A. Keller, P. L. Ferguson, S. VanBergen, E. Cooper, T. F. Webster and A. Blum, Environ. Sci. Technol., 2011, 45, 53235331.

4. Zheng T, Wang W, Liu Y . A novel phosphorusnitrogen flame retardant for improving the flame retardancy of polyamide 6: Preparation, properties, and flame retardancy mechanism. Polymers for Advanced Technologies, 2021(2).
5. J Liu, Dong C, Zhang Z, et al. Durable flame retardant cotton fabrics modified with a novel silicon-phosphorus-nitrogen synergistic flame retardant[J]. Cellulose, 2020, 27(15):9027-9043.

6. Chi Z, Guo Z, Xu Z, et al. A DOPO-based phosphorus-nitrogen flame retardant bio-based epoxy resin from diphenolic acid: Synthesis, flameretardant behavior and mechanism. Polymer Degradation and Stability, 2020, 176:109151.

7. He L, Xie B , Lai C, et al. Synthesis of PhosphorusNitrogen-Halogen Ternary Systems Flame Retardant and Its Application in PP. Engineering Plastics Application, 2016.

8. Kotov N A . Multilayer Thin Films: Sequential Assembly of Nanocomposite Materials. 2003

9. Kim Y S , Harris R, Davis R . Innovative Approach to Rapid Growth of Highly Clay-Filled Coatings on Porous Polyurethane Foam. Acs Macro Letters, 2012, 1(7):820-824.

10. Xue C H, Wu Y, Guo X J , et al. Superhydrophobic, flame-retardant and conductive cotton fabrics via layer-by-layer assembly of carbon nanotubes for flexible sensing electronics[J]. Cellulose, 2020, 27(6).

11. Majka T M, Witek M, Radzik P, et al. Layer-byLayer Deposition of Copper and Phosphorus Compounds to Develop Flame-Retardant Polyamide 6/Montmorillonite Hybrid Composites. Applied Sciences, 2020, 10(14):5007.

12. Zhang Y, Yang W. Synthesis and characterization of PEDMCD as a flame retardant and its application in epoxy resins. RSC Advances, 2021, 11.

13. Formation of self-extinguishing flame retardant biobased coating on cotton fabrics via Layer-byLayer assembly of chitin derivatives. Carbohydr Polym, 2015, 115:516-524. 